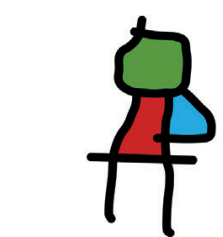

SEICAIP

\section{Allergologia et \\ immunopathologia}

Sociedad Española de Inmunología Clínica,

Alergología y Asma Pediátrica

www.all-imm.com

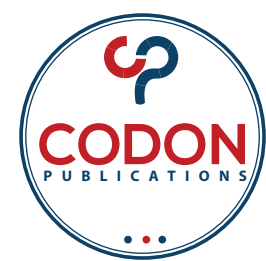

ORIGINAL ARTICLE

OPEN ACCESS CC(1)(2)

\title{
Association of Mycoplasma pneumoniae coinfection with adenovirus pneumonia severity in children
}

\author{
Jinfeng Wei ${ }^{\mathrm{a}}$, Suling Wu ${ }^{\mathrm{a}}$, Xuefeng Jin ${ }^{\mathrm{a}}$, Jie Zhanga Shanshan Pan ${ }^{\mathrm{b} *}$ \\ ${ }^{a}$ Department of Pediatric, Children's Hospital, Hangzhou, China \\ ${ }^{b}$ Department of Clinical Medicine, Hangzhou Medical College, Hangzhou, China
}

Received 2 July 2021; Accepted 27 October 2021

Available online 1 January 2022

\section{KEYWORDS \\ Adenovirus \\ pneumonia; \\ coinfection; \\ children; \\ Mycoplasma \\ pneumoniae}

\begin{abstract}
Between the winter of 2018 and the end of 2019, there has been an epidemic of adenovirus infection in southern China, including Zhejiang Province. The number of children suffering from adenovirus pneumonia (AP) has significantly increased. AP can be accompanied by Mycoplasma pneumoniae in children. This study aimed to investigate the association of $M$. pneumoniae and identify the risk factors for coinfection on hospitalized patients with AP. The patients were classified into two groups by etiologic analysis (single AP and AP with M. pneumoniae coinfection groups). The clinical manifestations, clinical medication, and laboratory and imaging findings of the two groups were compared and analyzed. The coinfection group $(n=125)$ had a significantly longer duration of fever than the single AP group $(n=171 ; P=0.03)$. Shortness of breath $(P=0.023)$ and pulmonary imaging findings, such as pulmonary consolidation, atelectasis, pleural effusion, and multilobe lesions $(P<0.05)$, were more common in the coinfection group. The patients with coinfection had more severe symptoms, significantly longer hospitalization time and an increased proportion of using glucocorticoids and/or immunoglobulin needing oxygen inhalation $(P<0.05)$. The incidence of AP with $M$. pneumoniae coinfection is high. The prolonged fever duration and pulmonary imaging findings could be used as prediction factors to predict M. pneumoniae coinfection in children with AP. Patients with AP coinfected with MP may easily develop severe illness. Hence, a reasonable change in the treatment is necessary.

(c) 2022 Codon Publications. Published by Codon Publications.
\end{abstract}

*Corresponding author: Shanshan Pan. Department of Clinical Medicine, Hangzhou Medical College, No. 481 Binwen Road, Hangzhou City, Zhejiang 310000; China. Email address: shanshanpan0512@126.com 


\section{Background}

Despite advances in prevention and management, pneumonia remains the leading cause of death in children outside the neonatal period. ${ }^{1}$ Community-acquired pneumonia (CAP) imposes a substantial burden on health services and is a primary cause of hospital referral and admission. According to 2010 statistics, approximately 265,000 deaths occurred because of CAP in hospitals, among which $99 \%$ occurred in developing countries. ${ }^{2}$ Therefore, it is pivotal to understand the clinic features caused by the possible pathogens of CAP. Currently, respiratory viruses are considered the most frequent etiologic agents. ${ }^{3}$

Adenovirus pneumonia (AP) is an important pathogen of CAP in children, accounting for $4 \sim 10 \%$ of CAP in hospitalized children. ${ }^{4}$ In severe cases, the manifestations of persistent high fever, severe cough, and progressive exacerbation of lung lesions may occur. Furthermore, chronic airway diseases such as bronchiolitis obliterans may be caused and persist. In recent years, the focus on the influence of adenovirus in respiratory tract infections in China has increased. ${ }^{5}$

Although Mycoplasma pneumoniae often causes subclinical respiratory infections, it can only be recognized for extra-pulmonary complications. ${ }^{6}$ M. pneumoniae is an important pathogen that causes CAP, accounting for $20-40 \%$ of CAP in children. ${ }^{6}$ Children sometimes get coinfected with both adenovirus and M. pneumoniae. ${ }^{8}$ In our study, we mainly analyzed the clinical feature of AP, investigated the related effects of $M$. pneumoniae coinfection on hospitalized patients with AP, and also identified the risk factors of those patients.

\section{Materials and Methods}

\section{Subjects}

The study was performed from 1 January to 31 December 2019 at Hangzhou Children's Hospital, a tertiary care hospital in Zhejiang. A total of 171 cases of single AP and 125 of coinfection with $M$. pneumoniae were enrolled during the year. Patients were enrolled for the study if they had symptoms like fever, cough, and wheezing; the presence of rales in lungs on physical examination; and confirmation of inflammation in the lungs by imaging. ${ }^{7}$ Then, the AP and $M$. pneumoniae were detected by a commercial polymerase chain reaction (PCR) assay.

\section{Inclusion criteria}

(i) age between 29 days and 18 years old, (ii) diagnosis of $A P$ according to the guidelines for the diagnosis and treatment of AP in children (2019 version) in China, ${ }^{5}$ (iii) positive detection of adenovirus antigen in nasopharyngeal secretion or sputum, and (iv) positive detection of $M$. pneumoniae immunoglobulin (Ig)M or M. pneumoniae nucleic acids in the nasopharyngeal aspirates or sputum.

\section{Methods}

Nasopharyngeal aspirates or sputum were collected at admission and detected for four pathogens: adenovirus (ADV); influenza A and Flu B; respiratory syncytial virus (RSV), using the diagnostic kit for virus antigen (Hangzhou Genesis Biodetection and Biocontrol Co., Ltd, China) by Colloidal gold methods. Then, the samples were assayed for M. pneumoniae DNA copy number using the $M$. pneumoniae fluorescent PCR diagnostic kit (Zhongshan University DaAn Gene Company, China). All the assays were performed according to the manufacturer's instructions. M. pneumoniae IgM was tested from the blood collected from patients simultaneously. To detect M. pneumoniae antibodies, a commercially available $M$. pneumoniae IgM enzyme-linked immune sorbent assay (ELISA) was performed (EUROIMMUN Medizinische Labordiagnostika AG, Germany). In addition, bacterial culture was also performed. The medical records of each patient, including demographic data, clinical features, laboratory tests (including biochemical examination etc.), and radiological results, were obtained. The study was approved by the Institutional Review Board of Hangzhou Children's Hospital (File No: 2019-14), and written informed consent was obtained from the parents of each patient. The clinical manifestations, laboratory and imaging findings, and clinical medication of the two groups were compared and analyzed.

\section{Statistical analysis}

The measurement data with a normal distribution was expressed as mean \pm standard deviation $(\alpha \pm S D)$, and a t-test was used to compare the difference between groups. Mann-Whitney $U$ test was used for intergroup comparisons. Counting data are expressed as the number (\%), and comparisons were made using the Chi-square test. $\mathrm{P}$ values were corrected for multiple comparisons using the Bonferroni procedure. $\mathrm{P}<0.05$ was considered statistically significant. Analyses were performed using SPSS v26.0 (SPSS, Chicago, IL).

\section{Results}

\section{Clinical characteristics of patients}

In total, 65,659 ADV antigens were performed during the year, with 5161 (7.9\%) ADV positive cases and 308 cases (6.0\% 308/5161) of AP diagnosed. Among 308 cases, 137 cases were coinfected with other pathogens, including M. pneumoniae (125 cases), influenza virus (5 cases), Streptococcus pneumoniae (1 case), and Haemophilus influenzae (2 cases). The overall coinfection rate was $44.48 \%$. M. pneumoniae (40.58\%) accounted for the most prevalent organism in coinfection cases. Two or more pathogens were detected in three patients, namely, $M$. pneumoniae +influenza virus (3 cases) and M. pneumoniae $+H$. influenzae (1 case). Among the 308 patients, a total of 171 patients were diagnosed with single AP and 
were enrolled in our study, with an average age of $3.28 \pm$ 1.90 years. Among these, 116 patients were male. In contrast, 125 patients were diagnosed with a coinfection of AP and M. pneumoniae, with an average age of $4.36 \pm 2.39$ years and 73 males. The age of the coinfection group was higher than that of the single AP group $(P=0.004)$, but no significant gender difference between the two groups was observed $(P=0.095)$. The incidence rates in the AP and coinfection groups were the highest in spring and summer, respectively, and there was a significant difference in the seasonal incidence rate $(P=0.001)$. The general characteristics of all patients are shown in Table 1.

\section{Clinical presentation}

The average fever duration was $6.22 \pm 2.17$ days, $7.10 \pm 2.98$ days in the AP and coinfection groups, respectively, indicating a significantly longer period of fever $(P=0.03)$. Twelve cases of shortness of breath were reported in the single AP group and 19 in the coinfection group, indicating that shortness of breath was more common in the coinfection group $(P=0.023)$ vs. the single AP group. As shown in Table 2, no significant differences in pulmonary signs, such as lung rales and wheezes, were observed between the two groups $(P>0.05)$.

\section{Laboratory and pulmonary imaging examination}

Table 3 shows that no significant differences in the blood tests, including leukocyte counts, C-reactive protein (CRP),

Table 1 General characteristics of the patients.

\begin{tabular}{|c|c|c|c|c|}
\hline & $\begin{array}{l}\text { AP group } \\
(\mathrm{n}=171)\end{array}$ & $\begin{array}{l}\text { Coinfection } \\
\text { group } \\
(n=125)\end{array}$ & $\chi^{2}$ & $P$ value \\
\hline \multicolumn{5}{|l|}{ Sex } \\
\hline Male & 116 & 73 & 2.786 & 0.095 \\
\hline Female & 55 & 52 & & \\
\hline \multicolumn{5}{|l|}{ Age* (years) $^{*}$} \\
\hline$<3$ & 82 & 45 & & \\
\hline $3-5$ & 58 & 36 & 11.306 & 0.004 \\
\hline$\geq 5$ & 31 & 44 & & \\
\hline \multicolumn{5}{|l|}{ Season\# } \\
\hline $\begin{array}{l}\text { Spring } \\
\text { (March-May) }\end{array}$ & 66 & 36 & & \\
\hline $\begin{array}{l}\text { Summer } \\
\text { (June-August) }\end{array}$ & 56 & 59 & & \\
\hline $\begin{array}{l}\text { Autumn } \\
\text { (September- } \\
\text { November) }\end{array}$ & 11 & 18 & 17.383 & 0.001 \\
\hline $\begin{array}{l}\text { Winter } \\
\text { (December- } \\
\text { February) }\end{array}$ & 38 & 12 & & \\
\hline
\end{tabular}

*Statistical difference in population distribution between the $\geq 5$ y ears group and the other two groups.

"Statistical difference in population distribution between summer and winter and autumn and winter, respectively.
Table 2 Symptoms and signs.

\begin{tabular}{lcccc}
\hline & $\begin{array}{c}\text { AP group } \\
(\mathrm{n}=171)\end{array}$ & $\begin{array}{c}\text { Coinfection } \\
\text { group }(\mathrm{n}=125)\end{array}$ & $\chi^{2}(\mathrm{t})$ & $\mathrm{P}$ value \\
\hline $\begin{array}{l}\text { Duration of } \\
\text { fever (days) }\end{array}$ & $6.22 \pm 2.17$ & $7.10 \pm 2.98$ & -2.955 & 0.03 \\
$\begin{array}{c}\text { Shortness of } \\
\text { breath }\end{array}$ & 12 & 19 & 5.157 & 0.023 \\
$\begin{array}{l}\text { Moist rales } \\
\text { Wheezing }\end{array}$ & 130 & 92 & 0.226 & 0.634 \\
\hline
\end{tabular}

procalcitonin (PCT), lactate dehydrogenase (LDH), hemoglobin $(\mathrm{Hb})$, albumin, alanine aminotransferase (ALT), and creatine kinase-MB (CK-MB) were observed between the two groups $(P>0.05)$. But pulmonary imaging findings, such as pulmonary consolidation, atelectasis, pleural effusion, and multilobe lesions, were more common in the coinfection group $(P<0.05)$ vs. the single AP group.

\section{Medication}

The patients with a coinfection of AP and M. pneumoniae had more severe symptoms than the single AP group, leading to a significantly longer hospitalization time and an increase in the proportion of patients using glucocorticoids and/or gamma globulin needing oxygen inhalation $(P<0.05)$. All children in the two groups recovered and were discharged without mechanical ventilation treatment(Table 4).

\section{Discussion}

From the winter of 2018 to the end of 2019, an epidemic of ADV infection occurred in southern China, including Zhejiang Province. The number of children suffering from CAP caused by ADV had increased significantly, which attracted the attention of the public and pediatricians. $A D V$ is a double-stranded DNA virus without a lipid envelope that is widely distributed in nature. It is mainly transmitted by air droplets and is an important pathogen that causes CAP in children. Severe or refractory ADV infection cases can cause a series of multiple organ injuries or even death. 8,9

M. pneumoniae because of its small cell size and volume (1-2 $\mu \mathrm{m}$ long and 0.1-0.2 $\mu \mathrm{m}$ wide) cannot individually be detected by light microscopy. ${ }^{12} \mathrm{M}$. pneumoniae was the most common atypical pathogen identified in CAP.13 Pneumonia caused by ADV is often accompanied by coinfection of M. pneumoniae. ${ }^{11}$

It is unknown whether adenovirus infection is related to the host's age and immune function, or whether coinfection complicates the clinical manifestations of AP.

AP is common in children aged between 6 months and 5 years, especially those under 2 years old, with higher occurrence in male patients than in females. ${ }^{10}$ In the present study, the age of patients in the single AP group vs. M. pneumoniae coinfection group was significantly younger, and likely because young children generally lack 
Table 3 Laboratory detection and imaging features. ${ }^{a}$

\begin{tabular}{|c|c|c|c|c|}
\hline & AP group $(n=171)$ & Coinfection group $(n=125)$ & $\chi^{2}(\mathrm{t}$ or $\mathrm{Z})$ & $P$ value \\
\hline WBC & $10.69 \pm 4.89$ & $9.93 \pm 4.76$ & 1.337 & 0.182 \\
\hline $\mathrm{CRP}>10 \mathrm{mg} / \mathrm{L}$ & 114 & 75 & 1.39 & 0.238 \\
\hline $\mathrm{PCT}>0.25 \mathrm{ng} / \mathrm{L}$ & 103 & 67 & 1.477 & 0.224 \\
\hline $\mathrm{LDH}$ & $354.75 \pm 151.71$ & $370.93 \pm 147.15$ & 0.916 & 0.36 \\
\hline Anemia $^{\mathrm{b}}$ & 4 & 3 & 0.001 & 0.873 \\
\hline Hypoalbuminemia & 3 & 7 & 3.272 & 0.07 \\
\hline Myocardial damage (CK-MB > 50U/L) & 5 & 6 & 0.71 & 0.399 \\
\hline Liver function damage (ALT > 50U/L) & 5 & 5 & 0.256 & 0.613 \\
\hline Lung Consolidation & 17 & 35 & 16.262 & $<0.001$ \\
\hline Hydrothorax & 3 & 8 & 4.356 & 0.037 \\
\hline Multilobar lung inflammation & 12 & 27 & 13.423 & $<0.001$ \\
\hline
\end{tabular}

aNormal range: WBC, 4-12*10^9/L; CRP, 0-10 mg/L; PCT, <0.25-25 ng/L; LDH, 0-250 mmol/L; Albumin, 35-55 g/L; Hypoalbuminemia: Albumin, <30 g/L; CK-MB, 0-25U/L; Myocardial damage: CK-MB > 50 U/L; ALT 0-50 U/L; Liver function damage: ALT > $50 \mathrm{U} / \mathrm{L}$.

${ }^{\mathrm{b} C}$ Criteria for anemia in neonate: $\mathrm{Hb}<145 \mathrm{~g} / \mathrm{L}, 1-4$ months; $\mathrm{Hb}<90 \mathrm{~g} / \mathrm{L}, 4-6$ months; $\mathrm{Hb}<100 \mathrm{~g} / \mathrm{L}, 6$ months-6 years; Hb $<110 \mathrm{~g} / \mathrm{L}, 6-14$ years; $\mathrm{Hb}<120 \mathrm{~g} / \mathrm{L}$.

WBC, white blood cells; CRP, C-reactive protein; PCT, procalcitonin; LDH, lactate dehydrogenase; Hb, hemoglobin; ALT, alanine aminotransferase; CK-MB, creatine kinase-MB

Table 4 Medication.

\begin{tabular}{|c|c|c|c|c|}
\hline & AP group $(n=171)$ & Coinfection group $(n=125)$ & $\chi^{2}$ & $P$ value \\
\hline Fever longer than 7 days & 46 & 50 & 5.655 & 0.017 \\
\hline Application of glucocorticoids and (or) immunoglobulin & 27 & 48 & 19.515 & $<0.001$ \\
\hline Oxygen inhalation & 8 & 15 & 5.402 & 0.02 \\
\hline Mechanical ventilation & 0 & 0 & & \\
\hline Severe illness & 12 & 17 & 6.043 & 0.014 \\
\hline
\end{tabular}

specific antibodies against ADV and M. pneumoniae commonly infected older children. ${ }^{11}$ Male patients were higher than females in both groups, but no significant differences in gender distribution were observed between the two groups. The distribution of ADV infection is global. The season is a critical factor affecting ADV infection. The seasonal distribution of ADV infection varies in different regions and climates. ${ }^{12}$ Our research shows that ADV infection occurs in all seasons throughout the year, with the lowest infection rate in autumn and the highest rates in spring and summer, consistent with previous literature. ${ }^{10,13}$ However, there was still a difference between the two groups. The incidence rates was the highest in spring and summer in the single AP and coinfection groups, respectively, consistent with the epidemic of $M$. pneumoniae worldwide. ${ }^{6}$ It was suggested to pay more attention on ADV and M. pneumoniae infection in the highest incidence season. Fever is a manifestation of the body's resistance to inflammation, often used to judge the progress or disease outcomes. Compared with the single AP group, although both groups of children had fever, those who were coinfected with MP had a longer fever duration. Thus, coinfection may prolong the time of pathogen clearance and aggravate the host immune response, showing more internal and exogenous pyrogen. Our study found that the proportion of shortness of breath in the coinfection group, which led to higher oxygen inhalation therapy, was significantly higher than the single AP group, similar to the results of previous research. ${ }^{14}$ Community-acquired respiratory distress syndrome toxin produced by $M$. pneumoniae can cause cellular inflammation, airway dysfunction, and varying degrees of decline in lung function. ${ }^{19}$ ADV infection may cause the following manifestations: moist rales or wheezing heard during physical examination, the white blood cells (WBC) can be normal, elevated, or decreased; the CRP and PCT can be increased or normal; the liver and kidney function are abnormal; and imaging examination can show large high-density shadow and pleural effusion changes. The present study showed that both the groups had similar pulmonary signs and laboratory test results, such as WBC, CRP, LDH, ALB, and CK-MB. Therefore, it is difficult to distinguish whether patients with AP are coinfected with $M$. pneumoniae based on pulmonary signs and routine blood tests. But the coinfection group was more likely to cause lung consolidation, atelectasis, pleural effusion changes, and multiple lung lobe lesions, which suggested that this infection could further aggravate the pulmonary inflammatory exudation in children with AP to some extent through direct injury or indirect immune reaction.

At present, cidofovir has been used to treat severe ADV infections, but the data are limited, and their efficacy is unconfirmed. ${ }^{15}$ Therefore, supporting symptomatic treatment is the primary therapy for patients with AP. Intravenous immunoglobulin can inhibit the production of cytokines, neutralize inflammatory factors, antigens, and toxins, and participate in the regulation of the 
immune response. Glucocorticoids can inhibit an excessive immune-inflammatory response. The previous study by Lim et al. ${ }^{9}$ confirmed that the use of glucocorticoids or immunoglobulins in the treatment of AP has a certain effect, which can reduce complications and improve prognosis. Azithromycin is currently the preferred treatment choice for M. pneumoniae infection in children. Globulin or corticosteroids may also be needed for severe or refractory infections. ${ }^{21,22}$ In our study, children in the AP group were chosen to be treated with atomization, sputum aspiration, hormone and /or immunoglobulins, oxygen inhalation, etc., and children in the coinfection group were treated with azithromycin acupuncture based on supportive symptomatic treatment. All patients were cured and discharged with no mechanical ventilation. Our results showed that the use of immunoglobulin and/or glucocorticoids in the coinfection group was more common than the single AP group. ADV has strong virulence that can cause high mortality and is the pivotal pathogen leading to severe pneumonia in children. Studies have found that the incidence of dyspnea in AP is as high as $40.7 \%$, even requiring Extracorporeal Membrane Oxygenation (ECMO) treatment. ${ }^{16,17}$ Our data indicated an increased occurrence of severe symptoms in the coinfection group than the single AP group. Hospitalization in the coinfection group was also prolonged accordingly, suggesting that mixed $M$. pneumoniae infection might be one of the risk factors for the severity of $A P$, similar to the results of previous studies. ${ }^{18}$ No death cases or cases using mechanical ventilation after active and appropriate treatment in either group, suggesting that the prognosis of most children with AP, whether mixed with M. pneumoniae infection or not, is good.

Nevertheless, this study has several limitations. First, this is a single-center study conducted for one year only. Second, the distribution of pathogens was greatly influenced by the region and climate. Third, the sample size was relatively small. Lastly, it is a retrospective study and lacks a rigorous design.

As mentioned above, AP coinfection with $M$. pneumoniae may lead to prolonged fever duration because of aggravation of the systemic inflammatory response, and M. pneumoniae infection may play a pivotal role in worsening AP disease in children. The key to improving the prognosis is the identification of a potential $M$. pneumoniae coinfection and fruitful antibiotic treatment usage against it when detected.

\section{Disclosure Statement}

The authors report no conflict of interests.

\section{Funding}

This work was supported by the Natural Science Foundation of Zhejiang Province (grant number LQ20H040001) and the Medical Science and Technology Program of Zhejiang Province (grant number 2021KY932). The funding source played no role in the study design, data collection, data analysis, data interpretation, writing of the article, or in the decision to submit the article for publication.

\section{Authors' contributions}

Conceptualization: Pan SS. Funding acquisition: Wei JF and, Zhang J. Investigation: Wei JF, Wu SL, and Zhang J. Writing (review and editing): Wei JF, Wu SL, Jin XF, and Pan SS.

\section{References}

1. Le Roux DM, Zar HJ. Community-acquired pneumonia in children-a changing spectrum of disease. Pediatr Radiol. 2017;47(11):1392-8. https://doi.org/10.1007/s00247-017-3827-8

2. Nascimento-Carvalho CM. Community-acquired pneumonia among children: the latest evidence for an updated management. J Pediatr. 2020;96:29-38. https://doi.org/10.1016/j. jpedp.2019.08.002

3. Yun KW, Wallihan R, Juergensen A, Mejias A, Ramilo 0 . Community-acquired pneumonia in children: myths and facts. Am J Perinatol. 2019;36(S 02):S54-7. https://doi. org/10.1055/s-0039-1691801

4. Jobran S, Kattan R, Shamaa J, Marzouqa $H$, Hindiyeh $M$. Adenovirus respiratory tract infections in infants: a retrospective chart-review study. Lancet. 2018;391:S43. https://doi. org/10.1016/S0140-6736(18)30409-4

5. Zaifang J, Chen W, Quan L, Yiji H, Zongqi D, Xin N, et al. Standards for diagnosis and treatment of adenovirus pneumonia in children (2019 edition). Chinese J. Infect Dis. 2019:3:1616. Chinese. https://doi.org/10.26549/yzlcyxzz.v3i5.4992

6. Waites KB, Xiao L, Liu Y, Balish MF, Atkinson TP. Mycoplasma pneumoniae from the respiratory tract and beyond. Clin Microbiol Rev. 2017;30(3):747-809. https://doi.org/10.1128/ CMR.00114-16

7. Zhou Y, Wang J, Chen W, Shen N, Tao Y, Zhao R, et al. Impact of viral coinfection and macrolide-resistant mycoplasma infection in children with refractory Mycoplasma pneumoniae pneumonia. BMC infect dis. 2020;20(1):633. https://doi. org/10.1186/s12879-020-05356-1

8. La Fay C, Bosdure E, Baravalle-Einaudi M, Stremler-Le Bel N, Dubus J-C, Mazenq J. Severe adenovirus pneumonia with hemophagocytic syndrome and respiratory failure. Arch Pediatr. 2020;27(7):383-5. https://doi.org/10.1016/j. arcped.2020.07.003

9. Lim LM, Woo YY, De Bruyne JA, Nathan AM, Kee SY, Chan YF, et al. Epidemiology, clinical presentation and respiratory sequelae of adenovirus pneumonia in children in Kuala Lumpur, Malaysia. PLoS ONE. 2018;13(10):e0205795. https:// doi.org/10.1371/journal.pone.0205795

10. Xie L, Zhang B, Xiao N, Zhang F, Zhao X, Liu Q, et al. Epidemiology of human adenovirus infection in children hospitalized with lower respiratory tract infections in Hunan, China. J Med Virol. 2019;91(3):392-400. https://doi. org $/ 10.1002 / j m v .25333$

11. Jain S, Williams DJ, Arnold SR, Ampofo K, Bramley AM, Reed $C$, et al. Community-acquired pneumonia requiring hospitalization among US children. N Engl J Med. 2015;372(9):83545. https://doi.org/10.1056/NEJMoa1405870

12. Bakir J, Juárez MdV, Lución MF, Areso MS, Viegas M, Mistchenko AS, et al. Clinical and epidemiological study of 
acute lower respiratory tract infections caused by adenovirus in hospitalized children. Nineteen years of active epidemiological surveillance. Arch Argent Pediatr. 2020;118(3):193-201. https://doi.org/10.5546/aap.2020.eng.193

13. Yao L-h, Wang C, Wei T-l, Wang H, Ma F-l, Zheng L-S. Human adenovirus among hospitalized children with respiratory tract infections in Beijing, China, 2017-2018. Virol J. 2019;16(1):1-8. https://doi.org/10.1186/s12985-019-1185-x

14. Jiang W, Wu M, Zhou J, Wang Y, Hao C, Ji W, et al. Etiologic spectrum and occurrence of coinfections in children hospitalized with community-acquired pneumonia. BMC Infect Dis. 2017;17(1):1-8. https://doi.org/10.1186/s12879-017-2891-x

15. Siew JX, Seah XFV, Chew YR, Thoon KC, Chong CY, Yung CF, et al. Epidemiology of adenovirus infections and outcomes of cidofovir treatment in severely III children.
J Pediatr Infect Dis.. 2020;39(10):907-13. https://doi.org/10. 1097/INF.0000000000002726

16. Liu C, Xiao Y, Zhang J, Ren L, Li J, Xie Z, et al. Adenovirus infection in children with acute lower respiratory tract infections in Beijing, China, 2007 to 2012. BMC Infect Dis. 2015;15(1):1-9. https://doi.org/10.1186/s12879-015-1126-2

17. Hage E, Huzly D, Ganzenmueller T, Beck R, Schulz TF, Heim A. A human adenovirus species $B$ subtype 21 a associated with severe pneumonia. J Infect. 2014;69(5):490-9. https://doi. org/10.1016/j.jinf.2014.06.015

18. Zhou Y, Wang J, Chen W, Shen N, Tao Y, Zhao R, et al. Impact of viral coinfection and macrolide-resistant mycoplasma infection in children with refractory Mycoplasma pneumoniae pneumonia. BMC Infect Dis. 2020;20(1):1-10. https://doi. org/10.1186/s12879-020-05356-1 